\title{
Anal intercourse: a risk factor for anal papillomavirus infection in women?
}

\author{
C L Law, C H Thompson, B R Rose, Y E Cossart
}

\begin{abstract}
Objective-To determine whether anal intercourse is a risk factor for anal HPV infection in women.

Design-Results derived from clinical examination, anal cytology and HPV DNA hybridisation were correlated with data obtained from a questionnaire administered to the patients at the time of their clinical examination.
\end{abstract}

Setting-A sexually transmitted diseases (STD) clinic in Sydney, Australia.

Subjects-31 women attending the clinic for HPV related problems.

Methods and Results-A thorough history was elicited from each woman followed by physical examination of the anogenital region. Cervical and anal scrapes were collected for cytology and HPV DNA hybridisation. Of the 15 women who practised anal intercourse, a total of $12(80 \%)$ had either clinical or subclinical HPV infection. Seven had overt anal warts, situated either internally or externally in the anal canal; and further 5 women had evidence of subclinical HPV infection as determined by positive cytological and/or HPV DNA hybridisation results on their anal scrapes. The women who did not have a history of anal intercourse had a lower $(7 / 16,43 \%)$, but not statistically significant, rate of anal HPV infection: five had anal warts and two had subclinical evidence of infection. No correlations were found between anal HPV infection and genital (cervical, vulval or vaginal) HPV infection; nor between the HPV typing patterns of women in either group.

Conclusion-The results obtained from these women do not indicate a close relationship between anal intercourse and the presence of detectable anal HPV infection.

Sydney STD Centre, Sydney Hospital

C L Law

Department of Infectious Diseases, Faculty of Medicine, The University of Sydney, NSW 2006 Australia

C H Thompson, B R Rose, Y E Cossart
Introduction

When male or female patients present with anal warts, their medical practitioners usually assume that these lesions were acquired as a result of receptive anal intercourse. This situation has arisen because anal warts were considered more common than penile warts in homosexual men, ${ }^{1}$ and most published reports on anal HPV infection have resulted from surveys carried out on this condition in homosexual populations. ${ }^{2-6}$ However, several studies have indicated that anal warts are more common than generally perceived in heterosexual men and women: a survey by Oriel $^{7}$ showed that $18 \%$ of women attending a STD clinic had anal warts; others by Goorney $e t a l^{8}$ and Evans and Fisk ${ }^{9}$ showed that $30 \%$ and $9 \%$ respectively of heterosexual men attending STD clinics had anal or perianal warts. In a recent study which we carried out on anal HPV infection in a group of homosexual men, no relationship was detected between the practice of receptive anal intercourse and either clinical or sub-clinical anal HPV infection. ${ }^{6}$ However, the validity of this observation required further investigation because those who admitted to receptive anal intercourse were over-represented (104 of the 112 subjects, $93 \%$ ). We therefore decided to study anal HPV infection in a different group of patients, where it was suspected that the practice of receptive anal intercourse would not be as prevalent.

The aim of this study was to determine the relationship between anal intercourse and anal HPV infection, according to well-defined clinical, cytological and molecular criteria, in a group of heterosexual women attending a Sydney sexually transmitted diseases (STD) clinic.

\section{Subjects and methods}

Study population

The study group consisted of female patients seen in the HPV Clinic of the Sydney STD Centre of Sydney Hospital between February 1987 and May 1988. Some were self-referrals, but many had been referred to the Clinic because of diagnosed or suspected HPV-related conditions, for example women with genital warts or atypical vulval/perineal lesions. In some instances women had been referred 
solely because of the presence of genital warts in their male partners. The project was approved by the Human Ethics Committee of The University of Sydney and informed consent was obtained from each subject prior to her entry into the survey.

\section{Clinical examination and specimen collection}

A thorough history regarding past STD infections and sexual history (particularly the practice of receptive anal intercourse) was elicited by direct interview at the first and subsequent visits. A significant number of women (24 out of the original 55 who were investigated) failed to provide information or provided inconsistent information concerning anal intercourse and were later excluded from the study. A complete gynaecological examination was performed by an experienced clinician (CL), at which time specimens for laboratory investigations were collected. The vulva and perineum were carefully inspected prior to the insertion of a disposable speculum for an internal examination of the vagina and cervix. The presence of condyomata or other visible abnormalities was recorded. Cervical scrapes for cytology (Papanicolaou smear) and HPV DNA hybridisation were obtained with modified Ayre's spatulae - the scrape for cytology was always collected prior to that for HPV DNA.

Anal examination consisted of a thorough inspection of the perianal skin with the patient in lithotomy position and the buttocks parted. This was followed by anoscopy using plastic disposable anoscopes with a Heine light source. The presence of external/ internal anal condylomata or any other abnormalities was noted. Cells from the squamo-columnar junction at the dentate line were obtained for cytology and HPV DNA hybridisation with the rounded edge of wooden tongue depressors which had been split in half.

When macroscopic lesions were detected in any of the ano-genital sites, biopsies were taken with the patient's consent under local anaesthesia ( $2 \%$ lignocaine $\mathrm{HCl}$ with 1:80 000 adrenaline) administered in a dental syringe with a $\mathbf{3 0}$ gauge needle. External condylomata were lifted with 25 gauge needles and then excised with curved iris scissors. Internal lesions were biopsied with Mini-Townsend (Baby Tischler) forceps. Biopsies (1-2 mm) for DNA hybridisation were immediately placed into collection buffer (10 mM Tris-HCl, $1 \mathrm{mM}$ EDTA, $0 \cdot 1 \%$ sodium azide, $\mathrm{pH} 7 \cdot 5$ ). The cervical and anal scrapes for cytology were smeared onto a glass slide and immediately fixed using Cytofix spray fixative. For HPV DNA hybridisations the. spatulae were broken off into tubes containing $1 \mathrm{ml}$ collection buffer, then stored at $4^{\circ} \mathrm{C}$ for a maximum of 48 hours prior to processing.
Cytology

The smears were stained by the routine progressive Papanicolaou stain, ${ }^{10}$ screened by a technologist, and then reviewed and reported by a cytopathologist. The presence of endocervical cells and columnar cells were used as indicators of adequate sampling of the cervical and anal mucosa respectively. ${ }^{11}$ The smears were assessed for evidence of HPV infection or features of CIN or AIN (cervical or anal intraepithelial neoplasia) according to well-accepted criteria ${ }^{12-14}$ and these were considered "positive". HPV infection was diagnosed on the basis of koilocytosis; or on the presence of at least three of the following features: binucleation, nuclear atypia, parakeratosis, hyperkeratosis, orangeophilia, amphophilia. Smears where no HPV-associated abnormalities were detected, those with inflammatory changes only, and those with only one or two of the cytological features mentioned were considered "negative".

\section{HPV DNA studies}

These were carried out as previously described. ${ }^{15}$ Briefly, washed cell pellets from the scrape specimens were simultaneously lysed and denaturated with 0.5 $\mathrm{M} \mathrm{NaOH}$ at $95^{\circ} \mathrm{C}$ for $10 \mathrm{~min}$. The lysates were then transferred to duplicate nylon membranes (GeneScreen Plus, NEN DuPont) using a Biodot ${ }^{\mathrm{TM}}$ apparatus (Biorad). Negative (10 $\mu \mathrm{g}$ foetal nucleic acids and $200 \mathrm{ng}$ pBR 322 DNA) and positive (125 pg-0.125 pg HPV DNA standards) controls were included in each run. For biopsy specimens, approximately $50 \mathrm{mg}$ tissue was finely minced and digested overnight in $600 \mu \mathrm{l}$ lysis buffer containing $0.5 \% \mathrm{SDS}$ and $100 \mu \mathrm{g} / \mathrm{ml}$ Proteinase $\mathrm{K}$. The nucleic acids from deproteinised digests were precipitated using ethanol/sodium acetate, then re-hydrated in 50 $\mu \mathrm{l}$ Tris-EDTA buffer $\mathrm{pH} 8 \cdot 0.5-10 \mu \mathrm{g}$ total extracted nucleic acids and $200 \mathrm{pg}$ HPV DNA standards were digested with Bam $\mathrm{Hl}$ (Pharmacia) then electrophoresed through a $0.7 \%$ agarose (Seakem) gel. Nucleic acid fragments were transferred to duplicate Genescreen Plus membranes by the alkaline transfer modification of the method of Southern.

Hybridisation was carried out under high stringency conditions as previously described..$^{15}$ Briefly, following prehybridisation for 2 hours, the membranes were incubated overnight at $65^{\circ} \mathrm{C}$ in hybridisation solution containing $2-3 \times 10^{6} \mathrm{cpm} / \mu \mathrm{g}$ denatured probe DNA (purified HPV 6/11 or $16 / 18$ DNA labelled with ${ }^{32} \mathrm{P}$-dCTP: each mixed probe was used for one of the duplicate set of membranes). The membranes were washed $3 \times 15 \mathrm{~min}$ in $2 \times \mathrm{SSC} /$ $0.1 \% \mathrm{SDS}$, and $3 \times 15 \mathrm{~min}$ in $0.2 \times \mathrm{SSC} / 0.1 \% \mathrm{SDS}$ at $65^{\circ} \mathrm{C}$, then autoradiographed for $3-5$ days at $-70^{\circ} \mathrm{C}$. 


\section{Statistical analyses}

Results were analysed univariately by the chi square test with the application of Yates' correction for small numbers.

\section{Results}

Consistent information regarding anal sexual intercourse was obtained from only 31 of the original 55 women who consented to participate in the survey: 15 of these gave a history of having anal intercourse at least once, while 16 denied such activity. Twenty six women of the total group $(84 \%)$ had a history of previous anogenital wart infection. There was no difference in the ages of the women in the two groups (mean age 29 years versus 27 years); nor was there any difference in the percentage of women with a past history of anogenital wart infection $(87 \%$ versus $81 \%$ ). Clinical examination revealed that 19 of the 31 women $(61 \%)$ had current overt anal or genital warts, although in four instances these lesions were only evident after the internal examinations (three women with internal anal warts only and one woman with vaginal warts only). Six women had concurrent anal and vulval or vaginal warts.

The data relating to detectable anal HPV infection are shown in table 1 . Of the women with a history of anal intercourse, $80 \%(12 / 15)$ were positive for HPV infection by one or more of the three criteria (that is, presence of visible anal warts, anal cytology or detection of HPV DNA). Four women were positive for anal HPV by all three criteria, four by two criteria and four by a single criterion. Seven $(47 \%)$ of these women had visible anal warts: three had both internal and external lesions; three had internal and one had external lesions only. The cytological and molecular investigations indicated that five of these women had subclinical anal HPV infection, positive results being obtained from one or both of these tests in the absence of overt warty lesions.

The women with no history of anal intercourse had a lower overall rate $(7 / 16,43 \%)$ of either clinical or subclinical anal HPV infection (table 1), although neither this difference nor the difference in the rates of overt warty infection between the two groups (that is, $7 / 15$ and $5 / 16)$ were statistically significant $(P>0.05)$. Only two of the women in this group had apparent subclinical anal HPV infection. Cytological features indicative of mild dysplasia (AIN I) were present in two women-one from each group (table 1).

Interestingly, the women with a history of anal intercourse had lower rates of genital HPV infection than those without such a history. Only four $(27 \%)$ of the former had vulval or vaginal warts and none had cytological evidence of cervical HPV, although HPV DNA was detected in the cervical scrapes of seven

Table 1 Detection of clinical (presence of visible warts) and subclinical (positive for cytological features of HPV and/or positive for HPV DNA) anal HPV infection in women with or without a history of anal intercourse

\begin{tabular}{|c|c|c|c|c|c|c|}
\hline \multirow[b]{2}{*}{$\begin{array}{l}\text { Patient } \\
\text { No }\end{array}$} & \multirow[b]{2}{*}{$\begin{array}{l}\text { Anal } \\
\text { intercourse }\end{array}$} & \multirow[b]{2}{*}{$\begin{array}{l}\text { Age } \\
\text { (years) }\end{array}$} & \multicolumn{2}{|c|}{ Anal warts } & \multirow[b]{2}{*}{$\begin{array}{l}\text { Anal } \\
\text { cytology }\end{array}$} & \multirow[b]{2}{*}{$\begin{array}{l}\text { Anal } \\
\text { HPV DNA }\end{array}$} \\
\hline & & & External & Internal & & \\
\hline 1 & + & 28 & - & - & + & + \\
\hline 2 & + & 33 & - & - & + & - \\
\hline 3 & + & 31 & + & + & - & + \\
\hline 4 & + & 40 & + & - & - & - \\
\hline 5 & + & 21 & - & - & - & + \\
\hline 6 & + & 23 & + & + & $-\dagger$ & + \\
\hline 7 & + & 39 & - & - & - & - \\
\hline 8 & + & 40 & - & - & + & - \\
\hline 9 & + & 25 & - & + & + & + \\
\hline 10 & + & 27 & - & + & + & + \\
\hline 11 & + & 24 & - & - & - & - \\
\hline 12 & + & 39 & - & + & + & + \\
\hline 13 & + & 19 & - & - & - & - \\
\hline 14 & + & 24 & - & - & + & + \\
\hline 15 & + & 22 & + & + & + & + \\
\hline 16 & - & 27 & - & - & - & - \\
\hline 17 & - & 26 & - & - & - & - \\
\hline 18 & - & 37 & - & - & - & - \\
\hline 19 & - & 28 & + & - & + & + \\
\hline 20 & - & 31 & - & - & - & - \\
\hline 21 & - & 32 & - & - & - & - \\
\hline 22 & - & 23 & + & - & - & - \\
\hline 23 & - & 27 & - & + & - & + \\
\hline 24 & - & 23 & - & - & - & + \\
\hline 25 & - & 19 & - & - & - & + \\
\hline 26 & - & 18 & - & - & - & - \\
\hline 27 & - & 24 & - & + & + & + \\
\hline 28 & - & 21 & - & - & - & - \\
\hline 29 & - & 34 & - & + & ++ & + \\
\hline 30 & - & 37 & - & - & - & - \\
\hline 31 & - & 23 & - & - & - & - \\
\hline
\end{tabular}

*Positive = HPV features identified; negative = normal, inflammatory, or 1-2 minor features only.

†Changes indicative of AIN I present in the anal scrapes from these patients. 
Table 2 High stringency HPV DNA typing results on specimens collected from the anus and genitalia

\begin{tabular}{|c|c|c|c|c|c|}
\hline \multirow[b]{2}{*}{ Specimen } & \multirow[b]{2}{*}{$N$} & \multirow[b]{2}{*}{ negative } & \multicolumn{3}{|c|}{ HPV DNA hybridisation } \\
\hline & & & $6 / 11$ only & $6 / 11 \mathcal{E} 16 / 18$ & $16 / 18$ only \\
\hline $\begin{array}{l}\text { anal warts } \\
\text { anal scrapes } \\
\text { vulval/vaginal warts } \\
\text { cervical scrapes }\end{array}$ & $\begin{array}{l}12 \\
31 \\
13 \\
31\end{array}$ & $\begin{array}{r}\overline{16} \\
1 \\
16\end{array}$ & $\begin{array}{l}7 \\
5 \\
5 \\
3\end{array}$ & $\begin{array}{l}4 \\
5 \\
5 \\
4\end{array}$ & $\begin{array}{l}1 \\
5 \\
2 \\
8\end{array}$ \\
\hline
\end{tabular}

women $(47 \%)$. In comparison, nine women $(56 \%)$ from the latter group had vulval/vaginal warts; and a total of $8(50 \%)$ had apparent cervical HPV infection-three $(23 \%)$ with cytological and molecular indications of HPV in their cervical scrapes, and a further five ( $31 \%$ ) with cervical HPV DNA detected.

As shown in table 2, high stringency HPV DNA hybridisation on the anal wart biopsies revealed the presence of HPV $6 / 11$ only in 58\%, HPV $16 / 18$ only in $8 \%$; and HPV $6 / 11$ together with HPV $16 / 18$ in $34 \%$ of the lesions; while hybridisation on the 15 HPV DNA-positive anal scrapes showed $33 \%$ were infected with HPV $6 / 11$ only, $33 \%$ had HPV $16 / 18$ only and a further $33 \%$ had both $6 / 11$ and $16 / 18$ present. In the genital tract, typing of the $15 \mathrm{HPV}$ DNA-positive cervical scrapes showed that $20 \%$ were infected with HPV $6 / 11$ only, $53 \%$ with $16 / 18$ only, and $27 \%$ with both HPV 6/11 and HPV 16/18. The results for the 13 women with vaginal or vulval warts showed that the distribution of HPV types in these lesions was not dissimilar to that seen in the anal warts (table 2). There were no differences in the typing patterns of the lesions from women with or without histories of anal intercourse, nor between lesions situated externally or internally.

\section{Discussion}

Anal HPV infection has acquired greater significance in the light of research which has shown that some of the causative papillomaviruses are frequently associated with both premalignant and malignant changes in the anal canal..$^{16}$ Of the 20 or more types of HPV which can infect the anogenital tract, HPV types 16 and 18 are frequently detected in tissues which have undergone transformation, whereas HPV types 6 and 11 are most often detected in benign warty lesions. ${ }^{1718}$ Most published surveys of anal HPV infection have centred on homosexual men, in whom very high rates of HPV infection, both overt and subclinical, have been demonstrated. ${ }^{2-6}$ However, it could be argued that this bias is unjustified, since it has been demonstrated that the rate of anal cancer-although highest in homosexual males-is in fact higher in women than in men overall. ${ }^{19}$ There is undoubtedly a need to elucidate the nature and epidemiology of anal HPV infection in both sexes, and to identify possible factors which not only contribute to its transmission, but also to the potential progression of simple infection to premalignancy or invasive cancer.

The finding that $48 \%$ of the women surveyed had engaged in anal intercourse at least once was unexpected in view of other reports which have reported the prevalence of anal intercourse as 15$20 \%$ in women attending STD clinics in the UK. ${ }^{20} 21$ and $25 \%$ in women attending for gynaecological services in the USA. ${ }^{22}$ This figure, which is approximately double that cited by others, is primarily due to the inclusion of those who had experienced anal intercourse only once and to a lesser degree by the inclusion of a small number of prostitute clients. It would have been interesting to stratify the analysis into those who had anal intercourse only once and those who had regular anal intercourse to investigate the likelihood of a "doseresponse" relationship between the practice of anal intercourse and the detection of anal warts but our numbers were too small to allow for this.

The survey described in this report attempted to investigate further the hitherto widely accepted theory that anal intercourse is largely responsible for the spread of anal HPV infection. The rate of clinical or sub-clinical anal HPV infection in the group of women we examined was very high $(19 / 31,61 \%)$, and was similar to that previously found in our study of homosexual men $(73 / 112,65 \%){ }^{6}$ despite the difference in the percentages of patients who practised receptive anal intercourse in the two groups ( $48 \%$ versus $93 \%$, respectively). Surprisingly, there was no statistically significant correlation between the practice of anal intercourse and the presence of detectable anal HPV infection in the group of women we examined, nor between the site of overt anal HPV infection (that is, site of warts either internal or external to the anal canal) and anal intercourse. Conversely, there was no clear association between anal HPV infection and HPV infection in the genital tract of the women. Interestingly, the rate of dysplastic change in the anal canal was lower in this group of women than in the homosexual men $(4 \%$ versus $19 \%) ;^{6}$ and no dysplastic changes greater than AIN I were seen in the females' anal smears, whereas $6 \%$ of the males' smears showed more severe dysplastic changes (AIN II) ${ }^{6}$ This may possibly be a reflection of the higher frequency of anal intercourse with multiple partners, chronic trauma from use of pleasuring devices or enemas, co-existent inflamma- 
tion due to anal herpes simplex or non-specific proctitis, ${ }^{23}$ or levels of immunosuppression due to HIV infection ${ }^{245}$ in homosexual men.

The high rate of both current and past HPV infection in the women surveyed was partially due to the selection bias inherent in a study of women attending an HPV clinic, and obviously indicates that the group is not representative of the general female population. Although some caution must be adopted in applying the conclusions resulting from this survey, the data which have emerged clearly do not support the notion that anal intercourse is the major factor responsible for the development of anal HPV infection. The proximity of the female genitalia and anus could readily permit extension of infection from one region to the other without any requirement for anal sexual contact with an infectious partner. In both men and women other factors-such as coexistent ano-genital STDs or other inflammatory conditions, and disturbances of general or local immunity ${ }^{24}$ - may be more important for the development of anal condylomata than any one particular type of sexual practice.

This project was supported by grants from the Sydney Hospital Foundation for Medical Research and the University of Sydney Cancer Research Committee. The cloned HPV DNAs were kindly donated by Professor $\mathrm{H}$ zur Hausen and colleagues, Heidelberg, Federal Republic of Germany. The authors thank G Holt, A Conlon and $\mathrm{K}$ Brake from the Sydney STD Centre for their clinical assistance and coding of data; Dr J Grace and the staff of the Department of Anatomical Pathology, Royal Prince Alfred Hospital for the cytological investigations; and E Sorich and A Piessse for their technical assistance with the DNA hybridisations.

Address for correspondence: Dr C Law, Sexual Health Clinic, St George Hospital, 1st floor, 36 Belgrave St, Kogarah, NSW 2217, Australia.

1 Oriel JD. Anal warts and anal coitus. $B r J$ Venereal Dis 1971;47:373-6.

2 Frazer IH, Medley G, Crapper RM, Brown TC, Mackay IR. Association between anorectal dysplasia, human papillomavirus and human immunodeficiency virus in homosexual men. Lancet 1986;ii:657-60.

3 Haye KR, Maiti H, Stanbridge CM. Cytological screening to detect subclinical anal human papillomavirus (HPV) infection in homosexual men attending a genitourinary medicine clinic. Genitourin Med 1988;64:378-82.

4 Kiviat N, Rompalo A, Bowden $\mathrm{R}$, et al. Anal human papillomavirus infection among human immunodeficiency virus sero-positive and sero-negative men. $J$ Infect Dis 1990;162:358-61.

5 Caussy D, Goederet JJ, Palefsky J, et al. Immune status as a determinant of human papillomavirus detection and its association with anal epithelial abnormalities. Int $J$ Cancer 1990;46:203-6.

6 Law CLH, Qassim M, Thompson CH, Rose BR, Grace J, Morris BJ, Cossart YE. Factors associated with clinical and subclinical anal human papillomavirus infection in homosexual men. Genitourin Med 1991;67:92-8.

7 Oriel JD. Natural history of genital warts. Br J Venereal Dis 1971;47:1-13.

8 Goorney BP, Waugh MA, Clarke J. Anal warts in heterosexual men. Genitourin Med 1987;63:216.

9 Evans DTP, Fisk P. AIDS and sex. Lancet 1988;i:59.

10 Koss LG. Diagnostic Cytology and its Histopathologic Basis. Lippencott Philadelphia. 3rd edn. 1979:1214.

11 Ford J, Anthanatos P, Grace J, Ng Ap, Law C. Cytological features of human papillomavirus in anal smears. Aust $J$ Med Lab Sci 1988;9:19-21.

12 Boon ME, Alors-von Kordelaar JJM, Rietweld Schaffers PEM. Consequences of the introduction of combined spatula and cytobrush sampling for cervical cytology. Acta Cytol 1986; 30:264-70.

13 Weid GL, Keebler GM, Koss LG, Reagen JW. In: Compendium of Diagnostic Cytology, 6th ed. Chicago, Tutorials of Cytology, 1988:96-104.

14 Meisels A, Fortin R. Condylomatous lesions of the cervix and vagina. I. Cytological patterns. Acta Cytol 1976;20:505-9.

15 Coppleson M, Rose BR, Sorich EA, et al. Human papillomavirus and cervical cancer: a clinical and laboratory study. $J$ Med Virol 1988;26:163-74.

16 Beckmann AM, Daling JR, Sherman $\mathrm{KJ}$, et al. Human papillomavirus infection and anal cancer. Int $J$ Cancer 1899;43:1042-9.

17 Syrjanen KJ. Human papillomavirus (HPV) infections of the female genital tract and their associations with intraepithelial neoplasia and squamous cell carcinoma. Pathol Ann 1986;21:53-89.

18 de Villiers EM, Wagner D, Schneider A, et al. Human papillomavirus infections in women with and without abnormal cervical cytology. Lancet 1987:2:703-6.

19 Daling J, Weiss NS, Hislop TG, et al. Sexual practices, sexually transmitted diseases, and the incidence of anal cancer. $N$ Eng J Med 1987;317:973-7.

20 Evans BA, McCormack SM, Bond RA, MacRae KD, Thorp RW. Human immunodeficiency virus infection, Hepatitis $B$ infection, and sexual behaviour of women attending a genitourinary medicine clinic. BMJ 1988;296:473-5.

21 Evans BA, Bond RA, MacRae KD. Sexual behaviour in women attending a genitourinary medicine clinic. Genitourin Med 1988;64:43-48.

22 Bolling DR. Prevalence, goals and complications of heterosexual anal intercourse in a gynecologic population. $J$ Reprod Med 1977;19:120-4.

23 Law CLH, Qassim M, Cunningham AL, Mulhall B, Grierson JM. "Non-specific" proctitis: association with human immunodeficiency in homosexual men. J Inf Dis (In press).

24 Tay SK, Jenkins D, Maddox P, Singer A. Lymphocyte phenotypes in cervical intraepithelial neoplasia and human papillomavirus infection. $B r J$ Obstets Gynaecol 1987;94: 16-21.

Accepted for publication 2 September 1991 